\title{
Experimental and numerical investigation of a long-duration Thermal Response Test: Borehole Heat Exchanger behaviour and thermal plume in the heterogeneous rock mass
}

\author{
G. Radioti*, B. Cerfontaine, R. Charlier, F. Nguyen \\ ArGEnCo department, University of Liege, Allée de la Découverte 9, 4000 Liege, Belgium
}

\section{A R T I C L E I N F O}

\section{Keywords:}

Thermal Response Test duration

High-resolution temperature measurements

3D numerical modelling

Heterogeneity

Closed-loop geothermal systems

\begin{abstract}
A B S T R A C T
This paper presents in-situ measurements of a long-duration Thermal Response Test (TRT) (heating phase of 7 months), conducted in a heterogeneous bedrock of conduction dominated heat transfer. The in-situ test was simulated by 3D numerical modelling, by assuming homogeneous and isotropic ground conditions considering the TRT data of the first few days. Based on the analysis of the experimental and numerical results, the behaviour of the Borehole Heat Exchanger for longer heating and recovery periods can be predicted based on the typicalduration TRT results. However, this behaviour is sensitive to the heat input variations, indicating the need for an accurate estimation of the energy needs of the building and the variable thermal loading during the operation of the system. Critical factors for the prediction of the temperature field evolution in the surrounding ground were detected based on the analysis of high-resolution temperature profiles. They include the distance to the heating source, borehole bottom end effects, bedrock heterogeneity and air temperature variations. Anisotropic effects are not detected, despite the expected anisotropic behaviour of the bedrock.
\end{abstract}

\section{Introduction}

Vertical closed-loop geothermal systems, also known as Borehole Heat Exchangers (BHEs), can provide economical and environmental benefits compared to other heating systems (Self et al., 2013), since they have low operating costs, high heat pump coefficient of performance and low $\mathrm{CO}_{2}$ emissions related to their operation. Subsurface characteristics are among the critical parameters for the design and the long-term behaviour of BHEs (MIS 3005; Luo et al., 2016). Though, in practice, they are often not adequately considered (Blum et al., 2011). This can result in increased capital costs, in the case of oversizing, and to malfunctions or short life spans, in the case of undersizing, overwhelming the potential and the applicability of these systems.

Thermal Response Tests (TRTs) allow to estimate the effective ground thermal conductivity including the influence of the in-situ conditions (Spitler and Gehlin, 2015). Determining the optimum duration of the test is critical, since it allows to minimize the cost by assuring the accuracy of the thermal conductivity estimation. Singorelli et al. (2007) conducted numerically TRTs and analysed the results by using the widely applied Infinite Line Source (ILS) model. They proposed that a test duration of $50 \mathrm{~h}$ can provide a satisfactory estimation of the ground thermal conductivity, in the case that groundwater effects are not dominant. Choi and Ooka (2016) analysed statistically 36 numerical TRTs influenced by various weather conditions, interpreted by the ILS model. They recommended a minimum test duration of $60 \mathrm{~h}$, to retain the ILS results error lower than $5 \%$.

The TRT results are used as input parameters for the modelling of the long-term behaviour of the system. Analytical models are widely used to simulate BHE behaviours and thermal plume in the surrounding ground (Philippe et al., 2009; Li and Lai, 2015). Each model is based on simplifying assumptions of BHE geometry, of boundary conditions, ground homogeneity or ground flow. Subsequently these models are often specialised to take into account short-term effects (Yavuzturk and Spitler, 1999) or long-term effects (Eskilson, 1987; Hellström 1991), heat advection in the ground (Diao et al., 2004; Erol et al., 2015), thermal effects associated with the finite length of the BHE (Philippe et al., 2009) or interactions between pipes of the BHE (Marcotte and Pasquier, 2008; Beier et al., 2013). However these methods suffer from several limitations regarding complex geometries, ground heterogeneity, grouting modelling or variable thermal loading. Finite element simulations allow to overcome these difficulties but the computational costs increases. The pioneering work of Al-Khoury (Al-Khoury et al., 2005; Al-Khoury and Bonnier, 2006) proposes to model the BHE as a 1D element and assumes a priori a thermal resistance within the grouting,

\footnotetext{
* Corresponding author.

E-mail address: gradioti@ulg.ac.be (G. Radioti).
} 

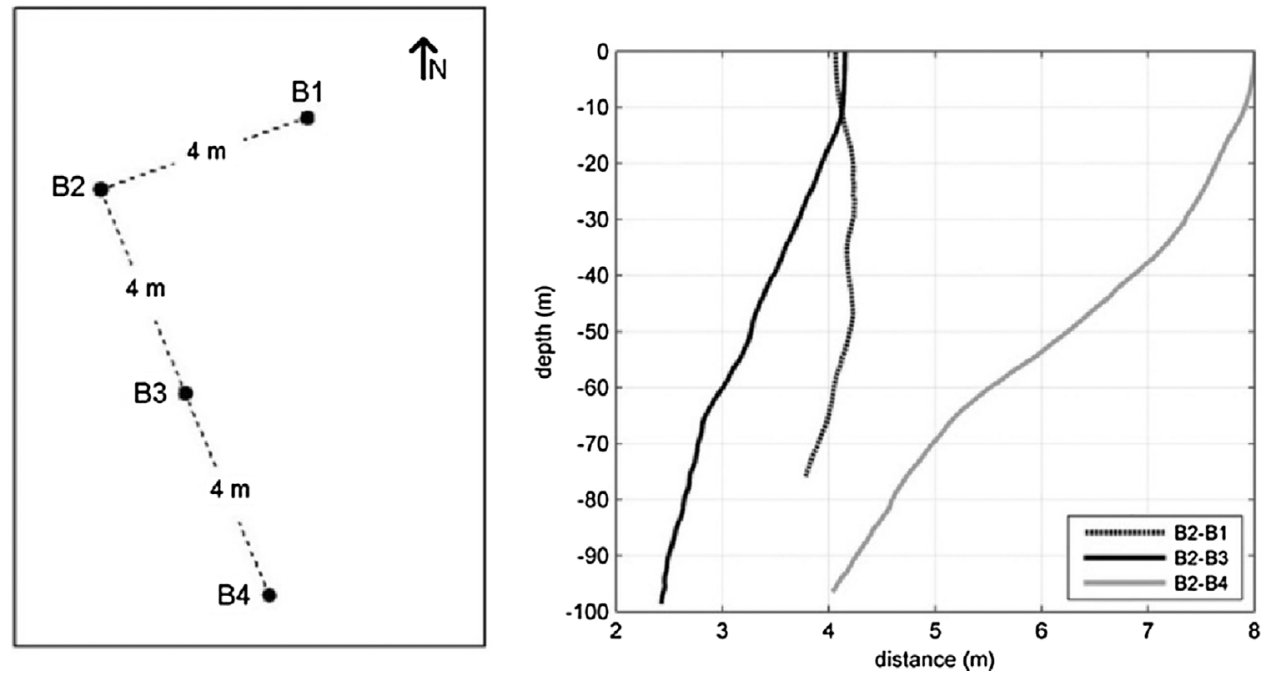

Fig. 1. Relative position of the four BHEs at the ground surface (left) and horizontal distance between B2 and the other three BHEs through depth (right). providing a tool to study long-term behaviour of BHE. Some other studies consider explicitly the behaviour of the grouting, allowing the study of transient short-term behaviour and temperature evolution close to the borehole (Ozudogru et al., 2015; Cerfontaine et al., 2016).

However, applying the TRT results to predict the behaviour of the system and the temperature field evolution in the surrounding ground remains challenging. The limited duration of the TRT presupposes that the results are representative of the ground thermal properties for longer heating periods and different applied modes. Moreover TRTs provide a depth-average value of the ground properties, which indicates that ground heterogeneity and anisotropy can be ignored. There is therefore the need for an experimental validation at real scale of these assumptions and of the evaluation of the modelling results.

This paper focuses on the extrapolation of the TRT results for longer heating and recovery periods and on the detection of the critical parameters for the simulation of the BHE behaviour and of the temperature field evolution in the surrounding ground. It presents a case study of a long-duration TRT (heating phase of 7 months), conducted in a conduction dominated, heterogeneous bedrock at the campus of the University of Liege (Liege, Belgium). During the test, temperature was measured at the pipe-inlet and outlet, as well as in the surrounding bedrock (by fiber optics in three observation BHEs). The in-situ test was simulated by 3D numerical modelling, by assuming homogeneous and isotropic ground conditions. The ground thermal conductivity was estimated by applying the ILS model of the first a few days (typical TRT procedure). We compare the numerical and the experimental results to evaluate the typical TRT duration and the validate the homogeneity assumption in a real case-study. Moreover, we study the effect of various factors on the temperature field evolution at the heterogeneous bedrock at the in-situ scale, based on this unique data set.

The remainder of the paper is organised as follows. First the site characteristics are presented together with the materials and methods used in this study. Then, the BHE behaviour is studied based on the comparison between the numerical and experimental results, focusing on the homogeneity assumption and the effect of the varying applied thermal load. Numerical and experimental data follow, concerning the thermal plume in the surrounding bedrock. Critical factors are detected and discussed. Finally conclusions are provided as well as a discussion on the applicability of the results in the case of dominant groundwater flow.

\section{Site set-up}

\subsection{Site description and geological settings}

The site consists of four double-U BHEs (namely B1-B4), of about
$100 \mathrm{~m}$ long, installed in 2013 on the campus of the University of Liege (Liege, Belgium). The relative position of the boreholes (B1-B4) was chosen as presented in Fig. 1 (left), in order to investigate any possible anisotropic thermal behaviour of the bedrock along two perpendicular planes: the first along the axis crossing $\mathrm{B} 1$ and $\mathrm{B} 2$ and the second along the axis crossing B2, B3 and B4. Azimuth and deviation were measured by magnetometers and inclinometers in the four boreholes with an orientation precision of $\pm 1.0^{\circ}$ and $\pm 0.5^{\circ}$ respectively. The horizontal distance between B2 and the other three boreholes was calculated based on theese data (Fig. 1, right). The distance between B2 and B1 oscillates around $4.1 \mathrm{~m}$. The distance between B2 and B3 decreases through depth, becoming almost the half at the bottom of the boreholes. This is also the case for the distance between B2 and B4. The bedrock consists mainly of siltstone and shale interbedded with sandstone layers and the average layer dip angle is approximately $45^{\circ} \mathrm{SE}$. A detailed bedrock characterisation based on borehole televiewer measurements, laboratory measurements and temperature profiles analysis is presented in Radioti et al. (2016).

The geothermal pipes were equipped with fiber optic cables in order to obtain continuous, high-resolution temperature profiles along the pipe loops (Radioti et al., 2013, 2015). Three different grouting materials were used in-situ: two commercial (B1, B2 and B3) and one homemade admixture with graphite (Erol and François, 2014).

\subsection{Materials and methods}

\subsubsection{TRT phases and measurements equipment}

Table 1 summarizes the different phases applied during the longduration TRT in B2. The heating phase had a total duration of 7 months, including two short interruption phases. The nominal heat input for the double-U configuration ( $42 \mathrm{~W} / \mathrm{m}$ length) was chosen according to the VDI 4640 propositions (for 2400 run hours and normal rocky

Table 1

Applied phases during the long-duration TRT in B2 (June 2015-June 2016).

\begin{tabular}{llll}
\hline time (d) & water circulation & heat injection & configuration \\
\hline $0-1.63$ & V & - & double-U \\
$1.63-95.18$ & V & $V$ & double-U \\
$95.18-95.61$ & - & - & - \\
$95.61-96.67$ & $V$ & - & double-U \\
$96.67-191.7$ & $V$ & $V$ & double-U \\
$191.7-192.6$ & - & - & - \\
$192.6-214.7$ & $\sqrt{ }$ & $V$ & single-U \\
$214.7-367$ & - & - & - \\
\hline
\end{tabular}




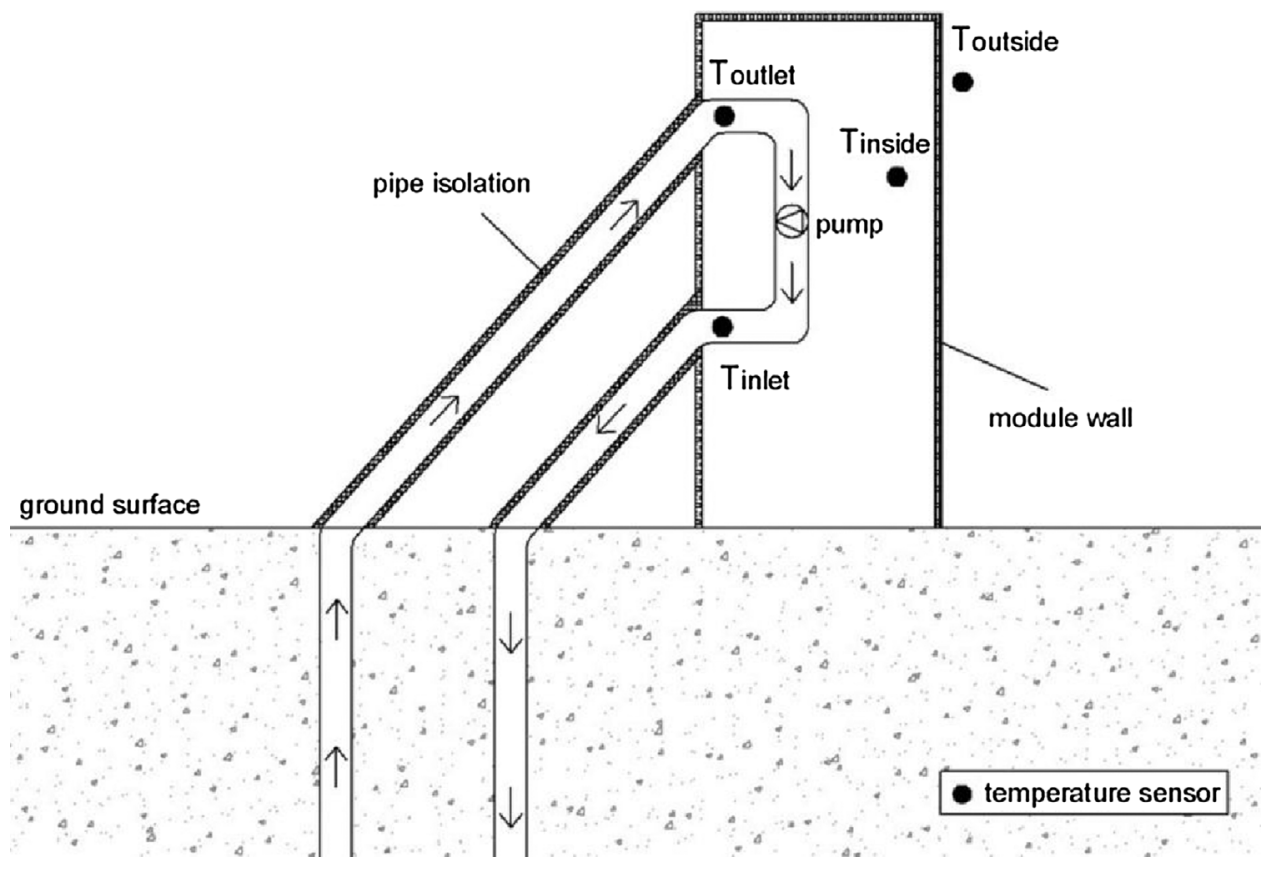

Fig. 2. Temperature sensors location during the TRT.

underground and water saturated sediment). During the single- $U$ heating, the total nominal power applied to the BHE decreased in half, which allowed to investigate the effect of a varying heat input on the water temperature evolution, as well as on the temperature field evolution in the surrounding rock mass. During the test, water and air temperatures were measured with an accuracy of $\pm 0.15^{\circ} \mathrm{C}$ (Class A) and $\pm 0.30^{\circ} \mathrm{C}$ (Class B) respectively (Fig. 2).

The actually applied heating power was calculated from the convective heat transfer equation, assuming that the temperature of the water remains constant during its circulation inside the connecting pipes (sufficiently insulated connecting pipes), as:

$q_{\text {appl }}=\dot{m} c_{p}\left(T_{w, \text { inlet }}-T_{w, \text { outlet }}\right)$

where $\dot{m}$ : the mass flow rate $(\mathrm{kg} / \mathrm{s})$,

$c_{p}=4.19 \mathrm{~kJ} / \mathrm{kgK}$ : the specific heat capacity of water at $10{ }^{\circ} \mathrm{C}$,

$T_{w}$, inlet: the temperature at the pipe inlet (exit of the rig) $\left({ }^{\circ} \mathrm{C}\right.$ ) and $\left({ }^{\circ} \mathrm{C}\right)$.

$T_{w}$,outlet: the temperature at the pipe outlet (entrance of the rig)

The applied power oscillates during the whole heating phase, following the air temperature oscillations (Fig. 3). This indicates the thermal interaction between the ambient air and the circulating water, attributed to the insufficient test rig insulation.

Temperature was measured by the fiber optics by applying the Distributed Temperature Sensing (DTS) technique (Hermans et al., 2014). Temperature was recorded every $20 \mathrm{~cm}$ (sampling interval) with a spatial resolution of $2 \mathrm{~m}$ in all the fiber optic measurements presented in this study. The temperature resolution (standard deviation) is of the order of $0.05{ }^{\circ} \mathrm{C}$. After obtaining each fiber optic profile, a Resistance Temperature Detector (RTD) probe (Class A, $\mathrm{T} \pm 0.15^{\circ} \mathrm{C}$ ) was lowered into the pipe loop and temperature was measured at certain depths. The RTD measurements served as reference values for the offset calibration of the corresponding fiber optic profiles, measured in B2 during the recovery phase and in the surrounding boreholes (B1, B3 and B4) during the whole test. The fiber optic cables are located at the outer surface of the pipes, sealed in the grouting materials. According to the exact location of the fiber in the borehole section, the temperature may vary and may be different from the RTD temperature. This would be the case in B2 during the heating phase. However, in the B2 borehole section during the recovery and in the other three borehole sections (B1, B3 and B4) during the whole test, the temperature can be assumed uniform. Hence, the exact location of the fiber in the borehole section has an insignificant impact on the calibration accuracy. The measurements accuracy is mainly controlled by the accuracy of the measurement equipment and any possible difference between the RTD depths and the corresponding fiber depths.

\subsubsection{Numerical modelling}

To simulate the in-situ TRT, a 3D numerical model was developed by using the finite element code LAGAMINE (Charlier et al., 2001; Collin et al., 2002). The BHE (B2) of $95 \mathrm{~m}$ length was modelled with depth discretisation of maximum $5 \mathrm{~m}$. The ground was extended $100 \mathrm{~m}$ below the borehole, covering a radial distance of $20 \mathrm{~m}$, including only conductive heat transfer. The generated mesh consists of 225000 nodes (4-node, 3D finite elements), including an explicit modelling of each BHE component.

The convective flow into each pipe leg is represented by a 1D finite element, following the depth discretisation of the 3D mesh. A detailed description and validation of the 1D finite element formulation is presented in Cerfontaine et al. (2016). The advection-diffusion in the pipe and heat diffusion in the borehole are modelled separately. 1D finite elements are used to simulate the first phenomenon. They discretise the pipes longitudinally by considering a constant fluid velocity and a homogeneous temperature for each pipe section. The convective radial heat transfer between heat carrier fluid and the borehole depends on a convective coefficient $h$ and the temperature difference between two nodes. The first node is representative of the fluid temperature (belongs to the 1D element) at a given depth. The second node is representative of the inner pipe wall temperature (belongs to the 3D mesh) at the same depth. The convective heat transfer coefficient, $h$, is calculated as:

$h=N u \cdot \lambda / D_{h}$,

where $D_{h}$ : the hydraulic diameter of the pipe $(m)$,

$\lambda$ : the fluid thermal conductivity $(W / m K)$ and

$\mathrm{Nu}$ : the Nusselt number (-)

The Nusselt number is the ratio of convective to conductive heat transfer across a boundary and for turbulent flow is given as (Gnielinski, 1976):

$N u=\frac{(f / 8)(\operatorname{Re}-1000) \operatorname{Pr}}{1+12.7(f / 8)^{1 / 2}\left(\mathrm{Pr}^{2 / 3}-1\right)}, \begin{aligned} & 0.5<\operatorname{Pr}<200 \\ & 3000>\operatorname{Re}>5 E 6\end{aligned}$ 

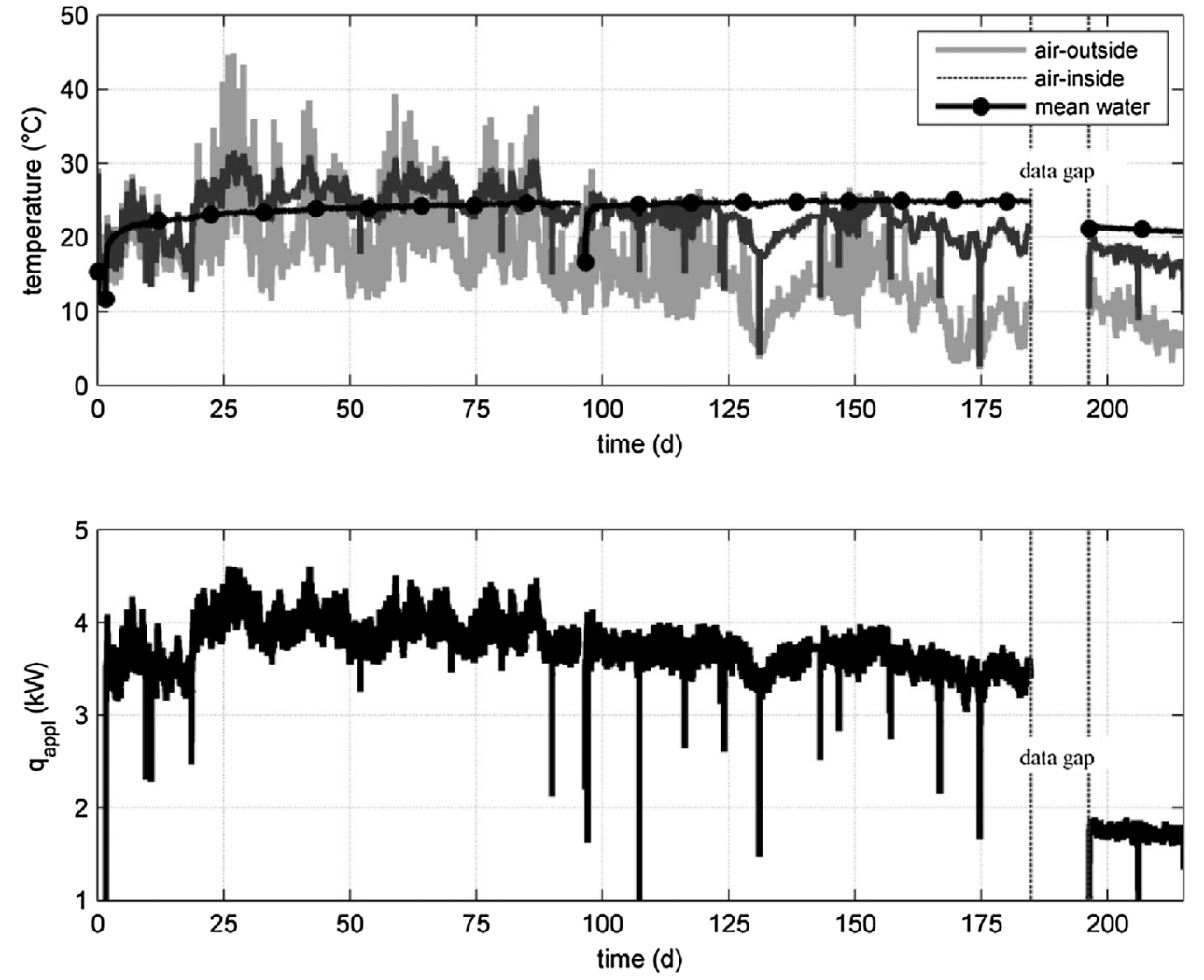

Fig. 3. Water and air temperature measurements (top) and applied heating power (bottom) during the long-duration TRT in B2 (June 2015- June 2016).
This relationship depends on the Reynolds number, $R e$, the Prandtl number, $P r$, and the Darcy friction factor, $f$. The Reynolds number is the ratio of inertial forces to viscous forces and classifies the flow as laminar, transient or turbulent. It is described as:

$\operatorname{Re}=\frac{\rho u D_{h}}{\mu}$,

where $\rho$ : the fluid density $\left(\mathrm{kg} / \mathrm{m}^{3}\right)$,

$u$ : the mean fluid velocity $(\mathrm{m} / \mathrm{s})$ and

$\mu$ : the fluid dynamic viscosity (Pa s)

The Prandtl number is a measure of diffusion with respect to the fluid velocity, defined as:

$\operatorname{Pr}=c_{p} \mu / \lambda$

where $c_{p}$ : the fluid specific heat $(\mathrm{J} / \mathrm{kgK})$.

The Darcy friction factor is defined, for smooth pipes, as:

$f=(0.79 \ln (\operatorname{Re})-1.64)^{-2}$.

In the $3 \mathrm{D}$ mesh the borehole geometry is explicitly considered, that allows to reproduce temperature gradients inside the borehole by avoiding any hypothesis on the borehole thermal resistance. The borehole mesh is composed of a grouting zone, a pipe zone and a water zone, covering the inner pipe sections. Heat diffusion is considered in all the zones. The central node of the water zone is coupled with the 1D finite element and this zone should not introduce any significant thermal resistance or capacity for the fluid. To ensure this, a sufficiently high thermal conductivity and a zero volumetric heat capacity was assigned to the 3D water elements. Heat is transferred by conduction from the central node, representative of the inner pipe temperature, to the grouting.

The interaction between the 3D mesh of the borehole and the 1D mesh of the pipes allows to simulate both the heating and the recovery mode. During the recovery phase, heat is physically transferred by radial conduction to the water inside the pipe, since the coefficient $h$ is theoretically equal to zero (fluid velocity is null). In our model, radial heat flux between the grouting and the pipes is considered purely convective. Therefore we consider a non-zero $h$ coefficient during recovery to allow heat transfer between the grouting and the water. This allows the numerical convergence of the solution without affecting the temperature distribution at the pipe section.

The thermal properties applied in the numerical model for the different phases of the test are summarised in Table 2. All the materials, including the surrounding bedrock, are assumed homogenous media and a uniform initial temperature $\left(11^{\circ} \mathrm{C}\right)$ was assumed for the whole model domain. No-heat flux boundary conditions were applied at the boundaries of the model, including the ground surface. The interaction between the ground and the ambient air is not included in this model. The total applied heating power was imposed as boundary condition at the pipe inlet.

The bedrock thermal conductivity was estimated based on the TRT data by applying the ILS model. The starting time point of the evaluated data was chosen at $10 \mathrm{~h}$. The choice of the starting time point is limited by the required time for the heat transfer inside the borehole to reach the steady-state phase and it should fulfil the mathematical limitation of the simplified ILS formulation, $t \geq 5 r_{b}{ }^{2} / \alpha$, where $r_{b}$ is the borehole radius $(m)$ and $\alpha$ the ground thermal diffusivity $\left(\mathrm{m}^{2} / \mathrm{s}\right)$. The ending time point was chosen at $60 \mathrm{~h}$ (typical TRT duration). The calculated thermal conductivity by this approach is equal to $2.90 \mathrm{~W} / \mathrm{mK}$ and is in good agreement with the corresponding values of TRTs in the other three BHEs (difference less than $0.1 \mathrm{~W} / \mathrm{mK}$; Radioti et al., 2016). The volumetric heat capacity was taken equal to $2300 \mathrm{~kJ} / \mathrm{m}^{3} \mathrm{~K}$, based on literature values for the in-situ rock types (Smolarczyk, 2003; Nguyen and Lanini, 2012). Therefore, the depth-average ground thermal diffusivity is $1.3 \cdot 10^{-6} \mathrm{~m}^{2} / \mathrm{sec}$. This value could fairly reproduce the water temperature slope of the experimental data. Then, the grouting thermal conductivity was estimated by trial and error fitting, considering the measurements of the first $60 \mathrm{~h}$ of the test. This estimation is based on the assumption that the in-situ BHE geometry (borehole radius, relative position of the pipe legs inside the borehole) is fairly reproduced in the numerical model. The estimated value $(1.0 \mathrm{~W} / \mathrm{mK})$ was in good 
Table 2

BHE geometry and materials properties for the numerical modelling in B2.

\begin{tabular}{|c|c|c|c|c|c|}
\hline & $\mathbf{h}_{\mathbf{1}}\left(\mathrm{W} / \mathrm{m}^{2} \mathrm{~K}\right)$ & $\mathbf{v}_{1}(\mathrm{~m} / \mathrm{s})$ & $\mathbf{h}_{\mathbf{2}}\left(\mathrm{W} / \mathrm{m}^{2} \mathrm{~K}\right)$ & $\mathbf{v}_{2}(\mathrm{~m} / \mathrm{s})$ & \\
\hline double U-pipe heating & 1385 & 0.30 & 1385 & 0.30 & \\
\hline single U-pipe heating & 5000 & 0 & 1957 & 0.43 & \\
\hline water circulation & 1519 & 0.32 & 1519 & 0.32 & \\
\hline recovery & 5000 & 0 & 5000 & 0 & \\
\hline $\mathbf{r}_{\text {bor }}(\mathrm{m})$ & 0.068 & $\lambda_{\text {pipe }}(\mathrm{W} / \mathrm{mK})$ & $0.42^{*}$ & $\lambda_{\text {grout }}(\mathrm{W} / \mathrm{mK})$ & 1.0 \\
\hline $\mathbf{r}_{\mathrm{p}, \text { inner }}(\mathrm{m})$ & 0.0131 & $\rho \mathbf{c}_{\rho, \text { pipe }}\left(\mathrm{kJ} / \mathrm{m}^{3} \mathrm{~K}\right)$ & $2083^{*}$ & $\rho \mathbf{c}_{\rho, \text { grout }}\left(\mathrm{kJ} / \mathrm{m}^{3} \mathrm{~K}\right)$ & $2500^{\text {** }}$ \\
\hline $\mathbf{r}_{\mathrm{p}, \text { outer }}(\mathrm{m})$ & 0.016 & $\mathbf{d}(\mathrm{m})$ & 0.045 & length (m) & 95 \\
\hline
\end{tabular}

* handbooks **handbooks, Delaleux et al. (2012).

agreement with the one proposed by the producers and measured in laboratory samples $(0.95 \mathrm{~W} / \mathrm{mK})$ (Erol and François, 2014). The estimated values for the bedrock and grouting thermal conductivity were assumed constant with depth and time during the whole test (heating and recovery phase).

\section{Results and discussion}

\subsection{BHE behaviour}

\subsubsection{Heating and recovery phase}

The BHE behaviour is represented by the water inlet and outlet temperature evolution. Figs. 4 and 5 compare the measured and the numerically obtained temperature evolution during the heating phase and the recovery phase respectively. Based on the good agreement between the experimental and numerical data, we can conclude that the mean effective ground thermal conductivity does not vary significantly with time during both applied modes (heating and recovery). Moreover, the ground thermal conductivity by the typical TRT data interpretation
(ILS model, test duration of $60 \mathrm{~h}$ ) can be applied to predict the BHE behaviour for longer heating periods and different applied modes (heating/recovery). The ground homogeneity assumption is valid concerning the BHE behaviour, despite that the bedrock is quite heterogeneous with varying thermal properties with depth (Radioti et al., 2016). It should be noted that these results are limited to conductiondominated heat transfer conditions in the ground.

\subsubsection{Effect of heat input interruptions}

Fig. 6 shows the temperature evolution before and after the first heat input interruption. Water temperature increases at a high rate for the first $36 \mathrm{~h}$ ( $96.7 \mathrm{~d}<\mathrm{t}<98.2 \mathrm{~d}$ ), equal to the duration of the recovery phase. However, after $36 \mathrm{~h}$ of heating, water and ground temperature is lower than the one reached before the interruption. For the rest of the heating phase, heat is progressively transferred to the surrounding ground, while the water temperature remains lower than the expected one, obtained by extrapolating the temperature evolution of the first heating phase. Despite that the same nominal heating power was applied during both phases, the mean applied power of the second

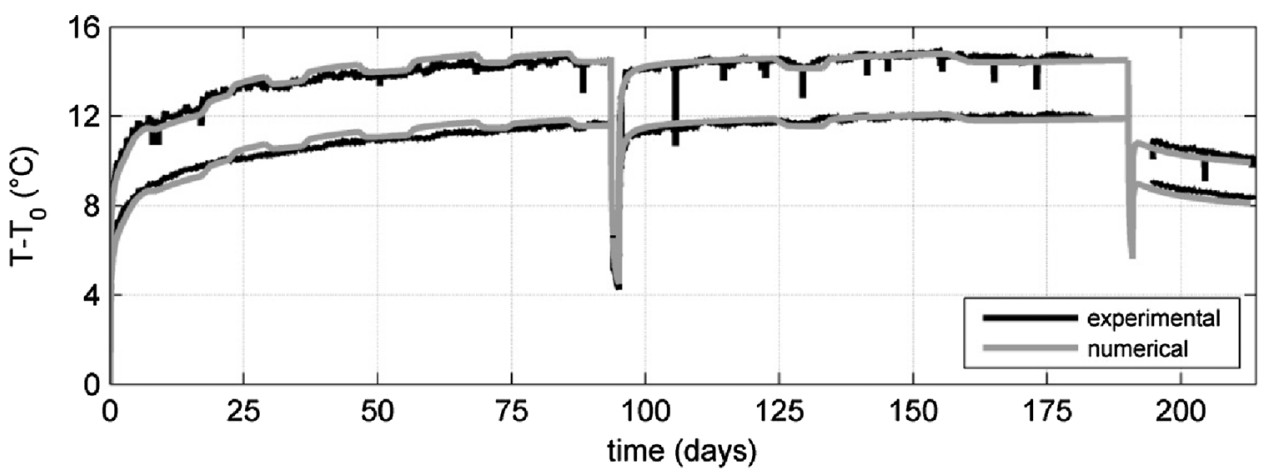

Fig. 4. Experimental and numerical water temperature evolution (top) and applied heating power (bottom) during the heating phase in $\mathrm{B} 2$.

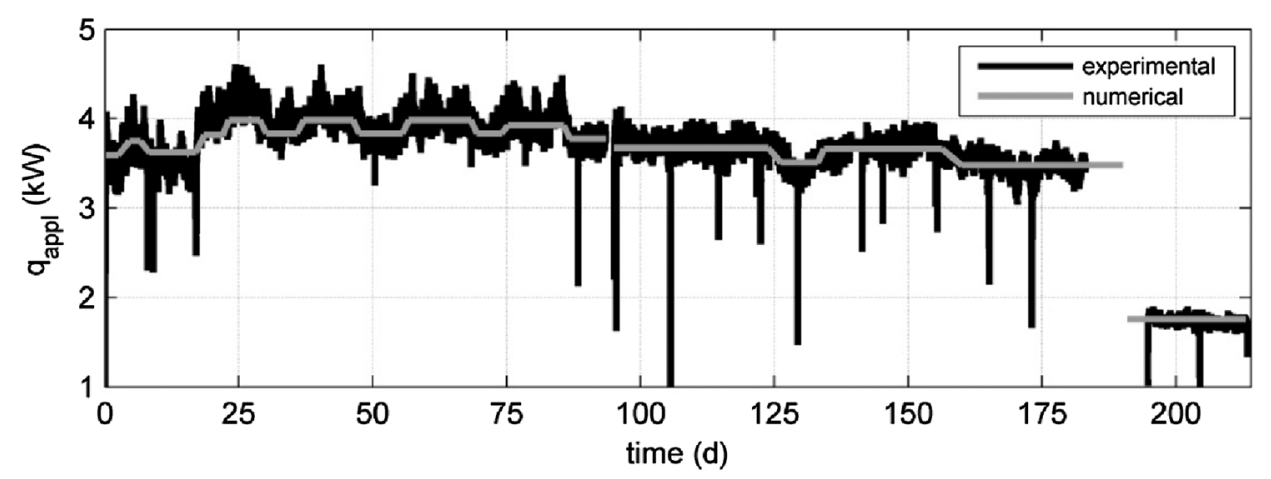



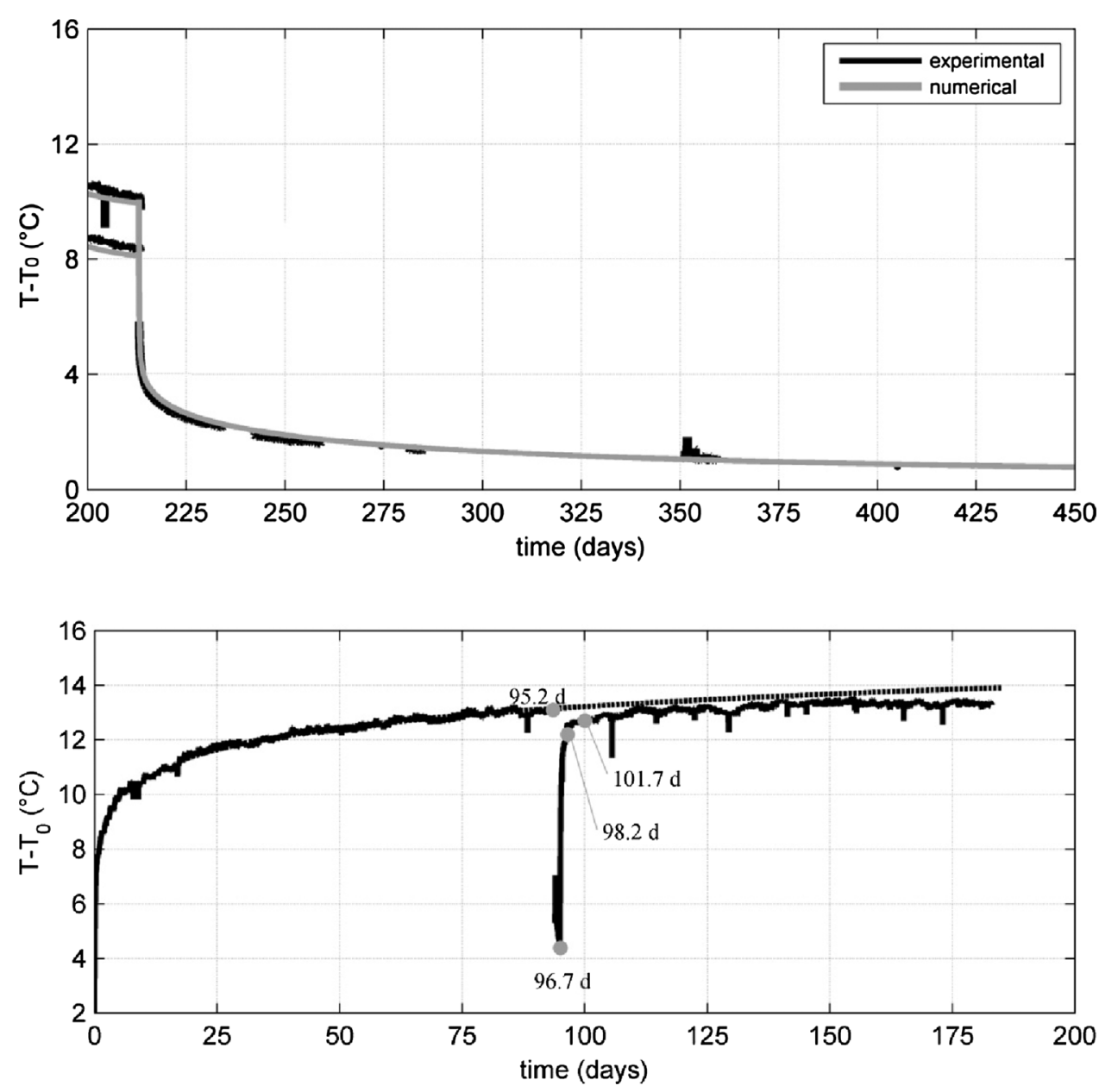

Fig. 5. Experimental and numerical temperature evolution during the recovery phase in $\mathrm{B} 2$ (numerical data: pipe inlet and outlet water temperature, experimental data: depth-average fiber optic temperature). heating phase $(3.60 \mathrm{~kW})$ is lower than the one of the first heating phase $(3.88 \mathrm{~kW})$, due to the thermal interaction with the ambient air (section 2.2.1). This could explain the lower than expected measured water temperature during the second heating phase.

Fig. 7 shows the temperature evolution at the surrounding ground before and after the second heat input interruption. In this case, the total heat input in the BHE was decreased in half. As also observed after the first heat input interaction, water temperature increases at a high rate for the first $20 \mathrm{~h}(192.6 \mathrm{~d}<\mathrm{t}<193.5 \mathrm{~d})$, equal to the duration of the recovery phase. While heating continues, water temperature is not only lower than the one before the interruption, but also decreases with time. This is also observed in the numerical results, where a constant heat input was applied during this period. The decreasing water temperature is attributed to the non-uniform temperature field, developed by a higher applied heat input before the interruption. These results highlight the sensitivity of the water temperature evolution on a variable heating loading.

For both heating phases, the steady-state heat transfer at the whole borehole cross section is achieved after approximately $10 \mathrm{~h}$, based on the numerical results. This is included in the proposed range ( $1 \mathrm{~h}-12 \mathrm{~h}$ ) for normal borehole sizes and ground conditions, according to Spitler and Gehlin (2015).

\subsection{Temperature field evolution in the surrounding bedrock}

Fig. 8 shows the measured temperature evolution along B3 (length

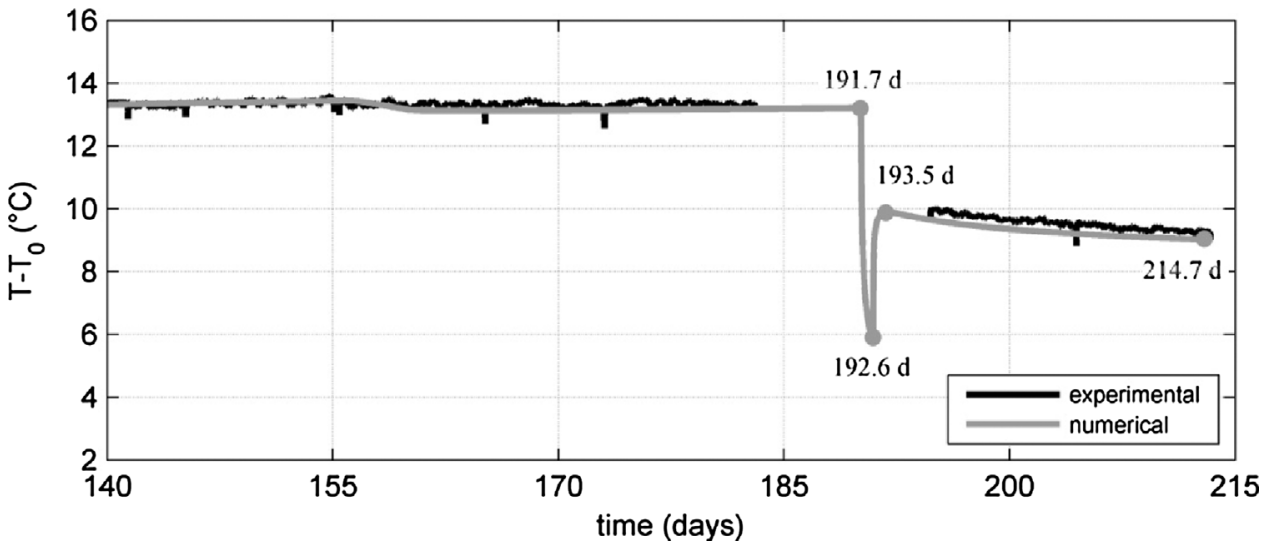

Fig. 7. Experimental and numerical water temperature evolution (mean of pipe inlet and outlet) before and after the second heat input interruption. 


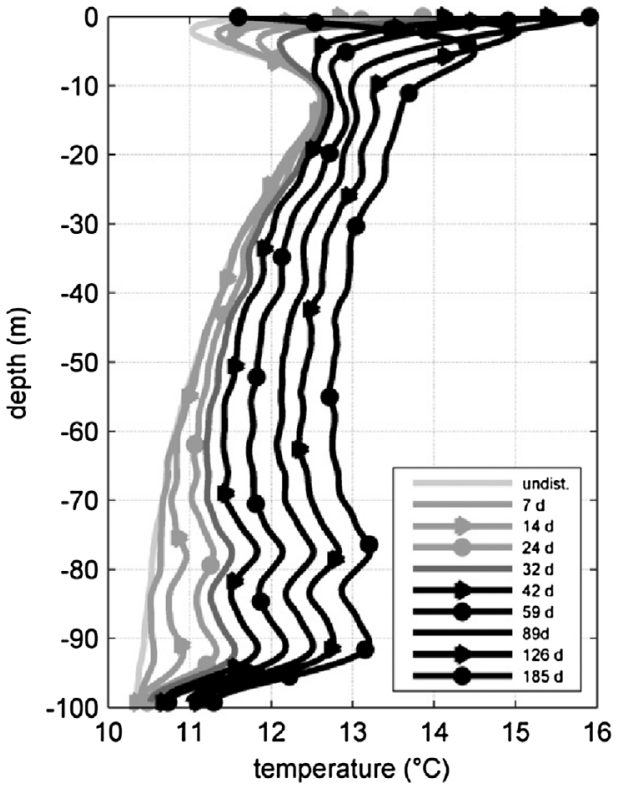

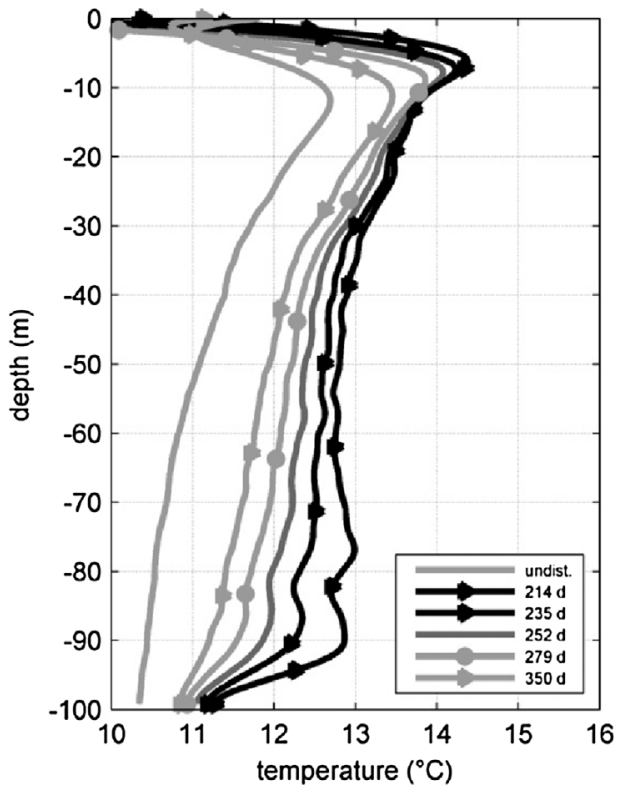

Fig. 8. Fiber optic temperature profiles in B3 during the double-U heating phase $(1.63 \mathrm{~d}<\mathrm{t}<191.7 \mathrm{~d})$ (left) and during the recovery phase $(\mathrm{t}>214.7 \mathrm{~d})$ (right). of $100 \mathrm{~m}$ ) during heating in B2 (length of $95 \mathrm{~m}$ ). B3 is characterised by two thick $(>6 \mathrm{~m}$ ) sandstone/siltstone layers at the lower part of the borehole (between 76 and $100 \mathrm{~m}$ depth) of high thermal diffusivity. In between them, shale/siltstone layers were detected of lower thermal diffusivity (Radioti et al., 2016). The negative gradient of the undisturbed ground temperature is attributed to the heat loss through structures into the subsurface, located close to the boreholes (Radioti et al., 2017).

In the first approximately $18 \mathrm{~m}$, ground temperature varies significantly, influenced by the ambient air temperature variations (thermally unstable zone). Temperature starts to increase at the location of the sandstone layers in the lower part of the borehole, since this part is closer to B2 than the upper part (Fig. 1) and these layers are characterised by a higher thermal diffusivity compared to the shale/siltstone layers. Temperature increases progressively at higher depths, where the distance to B2 increases, while heating continues. The two thick sandstone layers at the bottom of the borehole are clearly detected as local maxima in the temperature profiles, indicating the higher heat transfer rate along them. This is in good agreement with the geological context of the site and with the observations of the recovery profiles of a short-duration TRT conducted in B3 (Radioti et al., 2016). During the heating phase, temperature decreases at high rate in the last $10 \mathrm{~m}$ (90 m-100 m depth), despite that a sandstone layer is located at this depth. This is attributed to the length of the heating BHE (B2, $95 \mathrm{~m})$ and
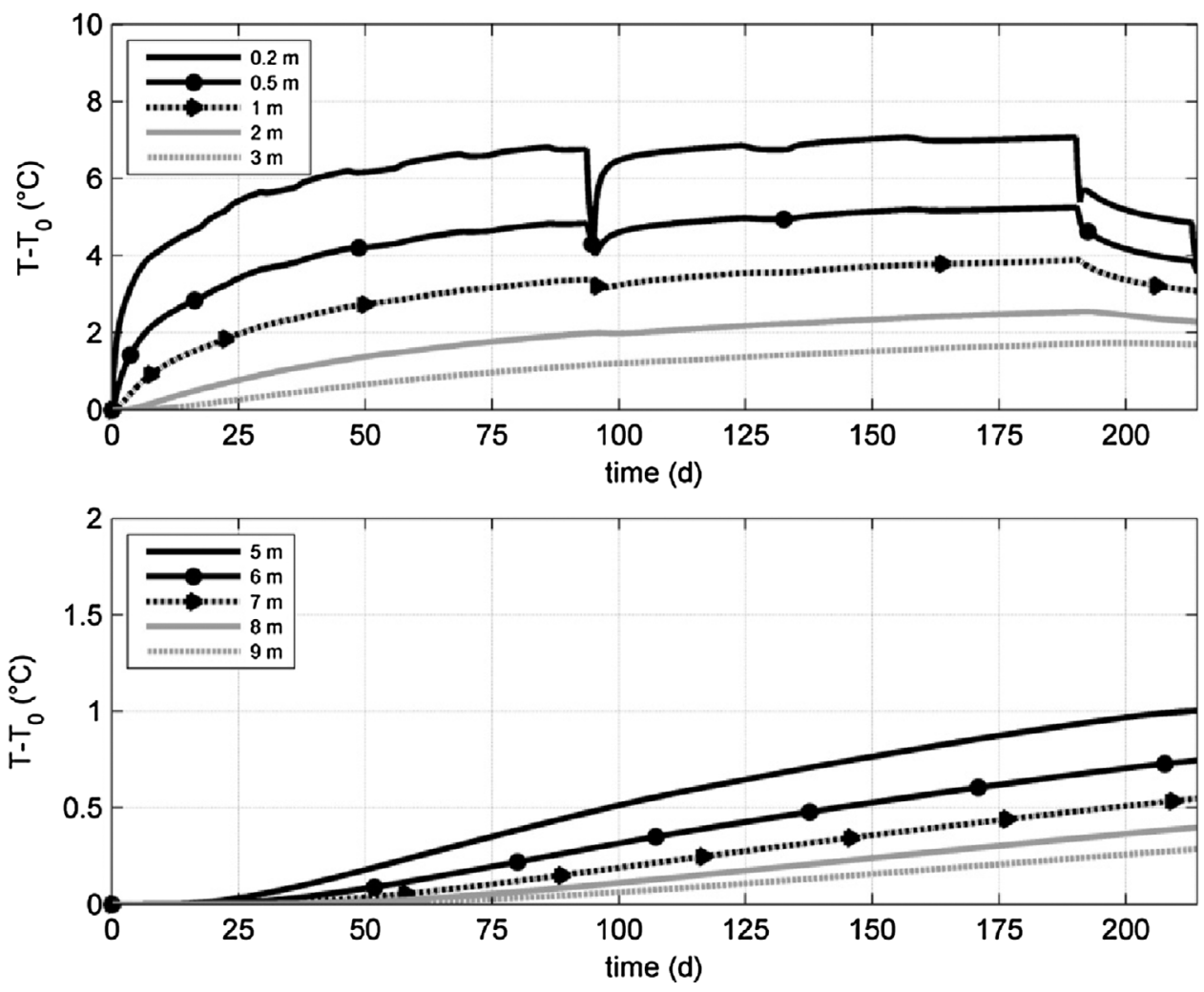

Fig. 9. Numerical temperature evolution in the rock mass for various distances from the heating source during the heating phase of the TRT in B2 $(\mathrm{z}=-50 \mathrm{~m})$. 
to the thermal effects at the borehole end that influence the temperature field close to the bottom of the borehole. During the recovery phase ( $t>214.7$ ), heat diffusion driven by the varying temperature in the rock mass progressively modifies the temperature profile, that tends to obtain the shape of the undisturbed profile (Fig. 8, right). The detected effects (distance to the heating source, bottom end effects, bedrock heterogeneity), as well as the possible bedrock anisotropy, are further studied in the following sections based on experimental and numerical results. The numerical results correspond to a uniform bedrock thermal conductivity of $2.9 \mathrm{~W} / \mathrm{mK}$ and thermal diffusivity of $1.3 \cdot 10^{-6} \mathrm{~m}^{2} / \mathrm{sec}$.

\subsubsection{Effect of distance to the heating source}

Fig. 9 shows numerical temperature results at various distances from the borehole center. The first $5 \mathrm{~d}$ of heating modify the temperature field at a distance lower than $2.5 \mathrm{~m}$ (DT $>0.01{ }^{\circ} \mathrm{C}$ ). This indicates that the effective ground thermal conductivity estimated based on the typical TRT procedure is representative of the ground mass expanding in a few meters around the BHE.

During the heating of the single- $U$ pipe, the total applied power in the BHE has decreased in half. Based on the numerical results, this resulted in a temperature decrease until a distance of approximately $3 \mathrm{~m}$ from the borehole center. This is verified by the in-situ fiber optic measurements in B3 (Fig. 10), where temperature decreases at a depth
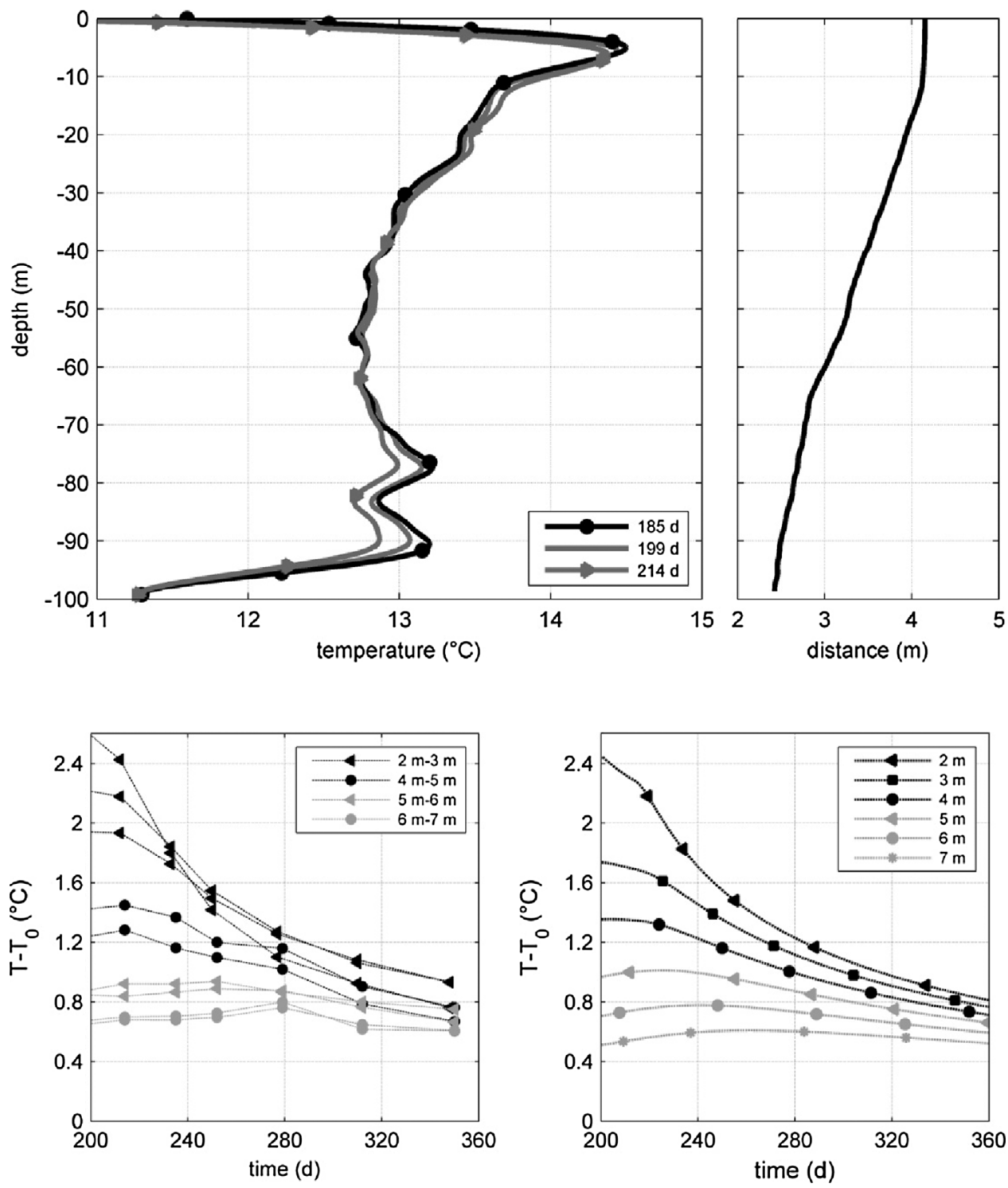

Fig. 11. Fiber optic measurements (left) and numerical results (right) during the recovery phase $(t>214.7$ d) for various distances from the heating source (depth for experimental data: $60 \mathrm{~m}, 70 \mathrm{~m}$, $90 \mathrm{~m}$ in B3 for $2 \mathrm{~m}-3 \mathrm{~m}$; $80 \mathrm{~m}, 85 \mathrm{~m}$ in B4 for $4 \mathrm{~m}$ $5 \mathrm{~m} ; 55 \mathrm{~m}$ and $60 \mathrm{~m}$ in $\mathrm{B} 4$ for $5 \mathrm{~m}-6 \mathrm{~m} ; 40 \mathrm{~m}$ and $45 \mathrm{~m}$ in $\mathrm{B} 4$ for $6 \mathrm{~m}-7 \mathrm{~m}$ ). 

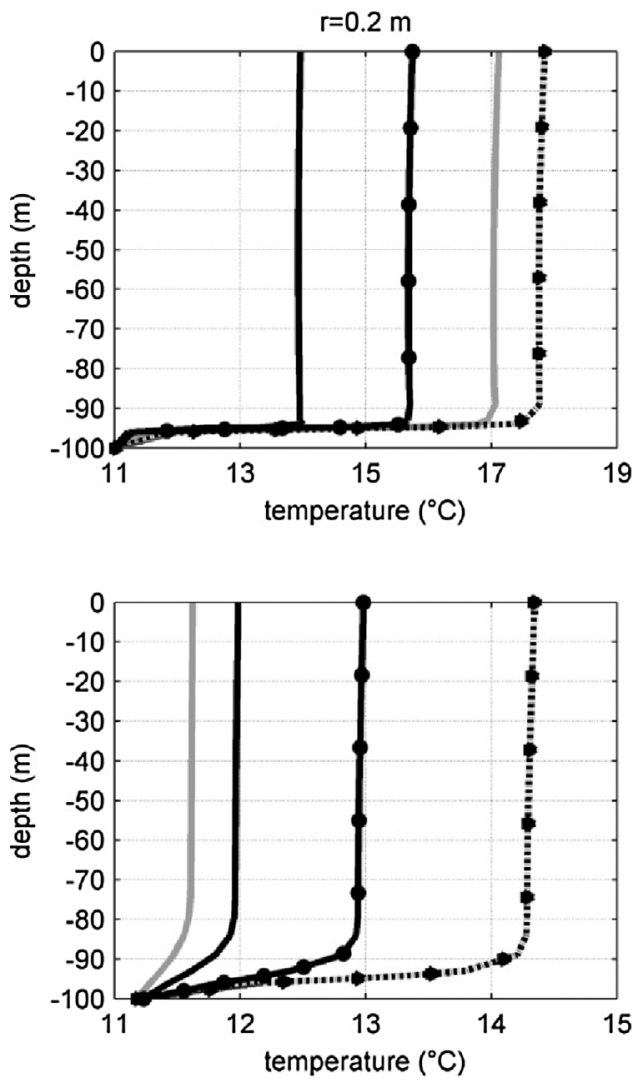

$t=95 d$
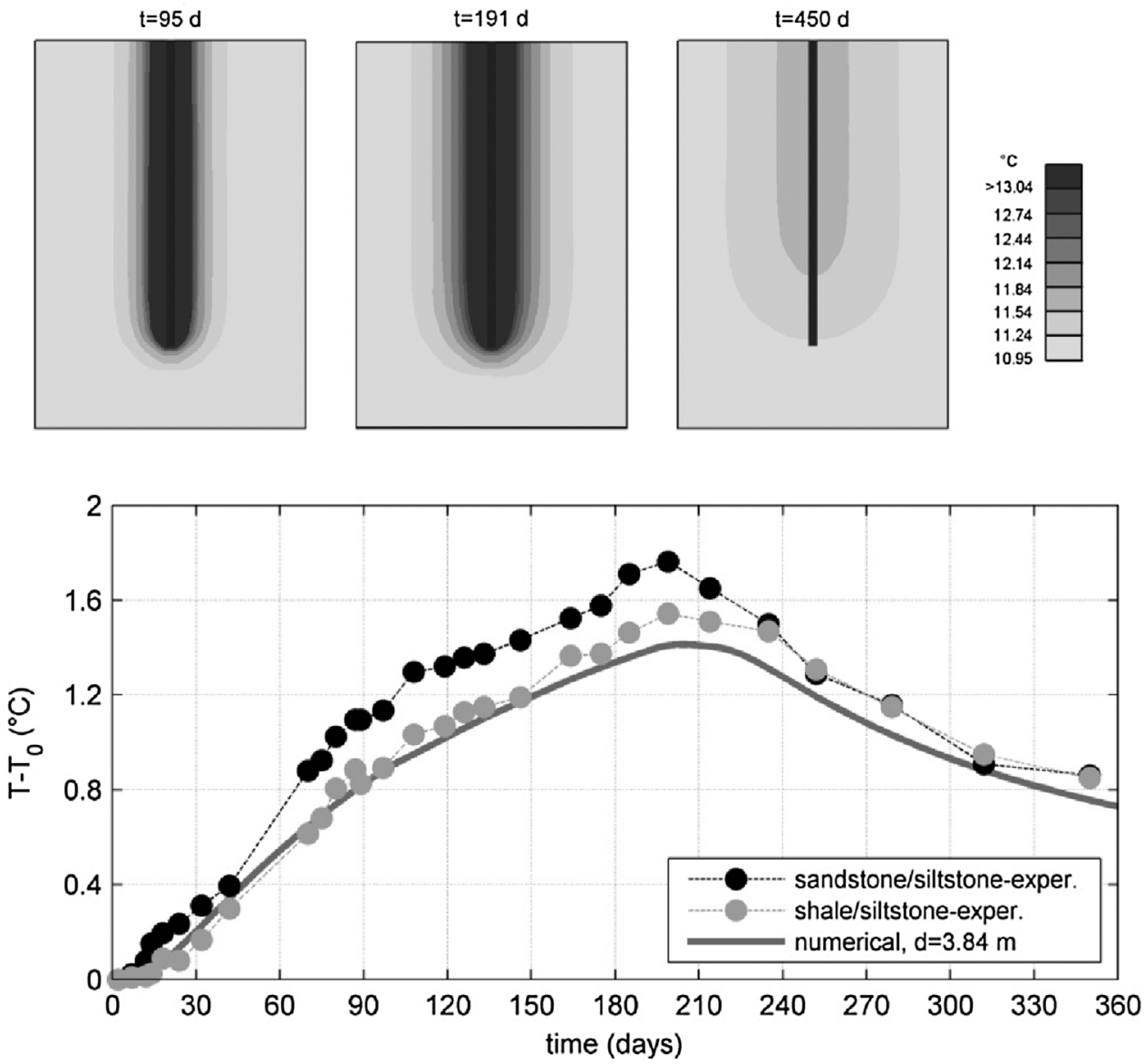

Fig. 12. Numerical results of thermal effects at the bottom end during the TRT in B2 (heating phase: $\mathrm{t}<214.7 \mathrm{~d}$, recovery phase: $\mathrm{t}>214.7 \mathrm{~d}$, borehole length: $95 \mathrm{~m}$ ).
Fig. 13. Temperature increase evolution at a sandstone/siltstone layer $(\mathrm{z}=-77.3 \mathrm{~m}, \mathrm{~d}=3.76 \mathrm{~m})$ and at a shale/siltstone layer $(\mathrm{z}=-68.4 \mathrm{~m}$, $\mathrm{d}=3.93 \mathrm{~m}$ ) in $\mathrm{B} 1$ during the TRT in B2. 

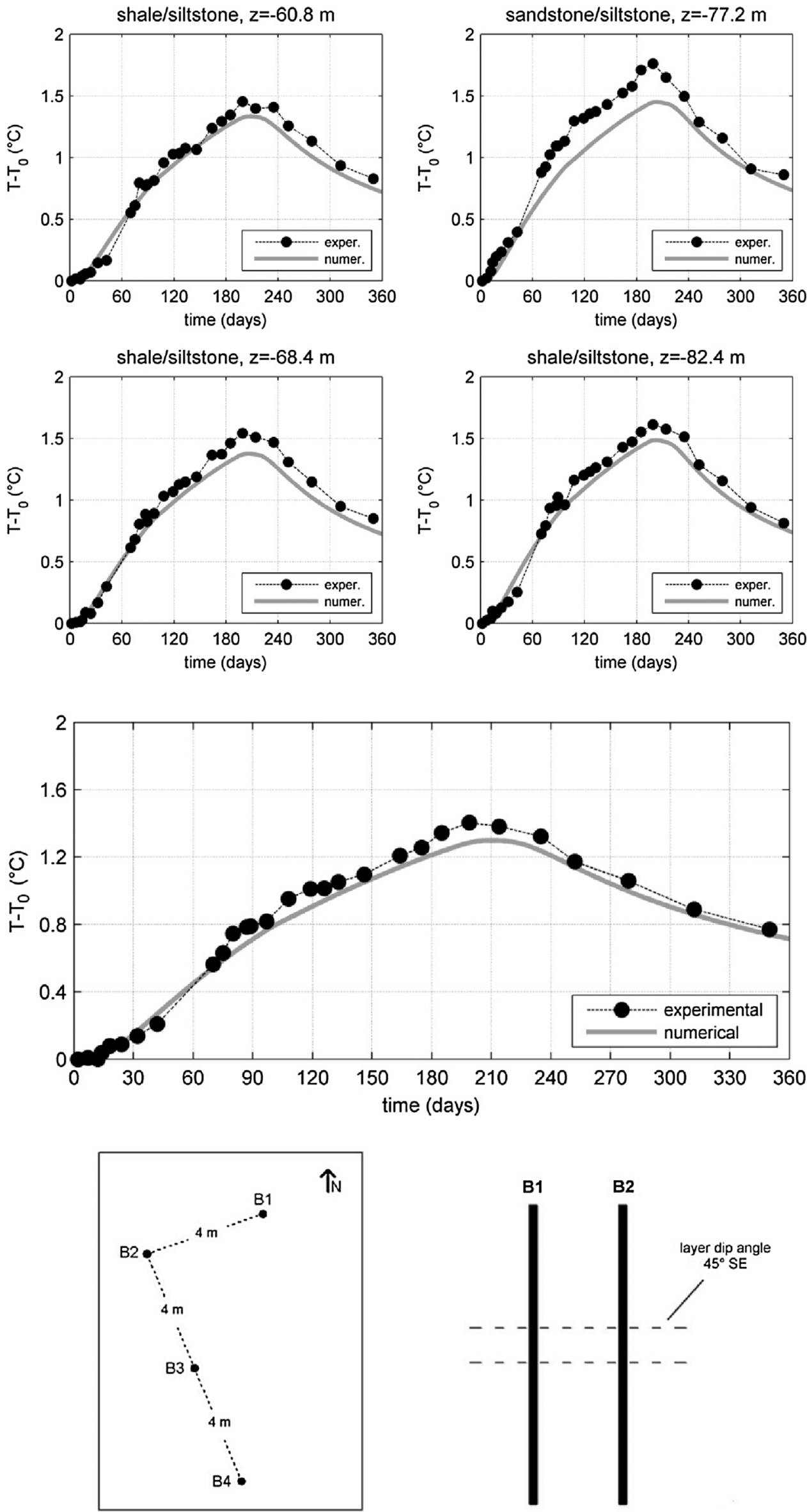

Fig. 15. Depth-average temperature increase evolution in B1 during the TRT in B2.
Fig. 14. Numerical and experimental temperature increase evolution at the center of thick layers (thickness $>3 \mathrm{~m}$ ) in $\mathrm{B} 1$.

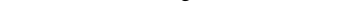


surrounding ground and that the ILS model is not valid in the ground surrounding the bottom of the borehole. Thermal end effects are observed close to the borehole (e.g. $\mathrm{r}=0.2 \mathrm{~m}$ ), as well as at greater distance (e.g. $r=5 \mathrm{~m}$ ) and are extended to lower depths with increasing heating time.

\subsubsection{Bedrock heterogeneity}

Fig. 13 shows the temperature evolution at the location of two successive layers, that have approximately the same distance to B2: a sandstone/siltstone layer (thickness of $6.5 \mathrm{~m}$ ) and a shale/siltstone layer (thickness of $4.4 \mathrm{~m}$ ). The higher heat transfer rate during the heating phase at the sandstone/siltstone layer is indicated by the higher temperature rise. During the recovery phase ( $t>214.7 \mathrm{~d}$ ), temperature becomes progressively uniform along the two layers. The heterogeneity effect is also displayed in Fig. 14, which shows the temperature evolution at the center of thick $(>3 \mathrm{~m}$ ) layers. For each layer, the experimental results are presented together with the numerical results, since the distance to the heating source is a critical factor for the temperature field evolution. The mean measured temperature for the sandstone/siltstone layer is higher of $0.23^{\circ} \mathrm{C}$ than the numerical one. In the shale/siltstone layers, this difference ranges between $0.12{ }^{\circ} \mathrm{C}$ and $0.16^{\circ} \mathrm{C}$. These results indicate that heterogeneity effects could be also important for the study of the thermal interaction between BHEs.

\subsubsection{Bedrock anisotropy}

Shale, and in a small extend siltstone, consists of foliations and displays an anisotropic thermal behaviour depending on the direction of the heat flow with regard to the foliations orientation. The thermal conductivity parallel to the foliations is up to 2.5 times higher than the one perpendicular to the foliations (Popov et al., 1999; Eppelbaum et al., 2014). By assuming that the foliations are oriented parallel to the bedding planes, heat is transferred parallel to the foliations along the B1-B2 plane. Along the B2-B3-B4 plane, heat flows at an angle of approximately $45^{\circ}$ with regard to the bedding planes. This indicates that temperature is expected to increase at a higher rate along the B1-B2 direction than along the B2-B3-B4 direction. The three observation boreholes (B1, B3 and B4) have a different distance to the heating source, which is a controlling factor for the temperature filed evolution. Hence, the measured temperature profiles cannot be directly compared with each other to investigate the possible anisotropy effect. For this reason, the measured temperature data are studied in the following using as reference the numerical results. The numerical results include the influence of the distance to the heating source, but not anisotropic effects, and would allow by comparing them to the experimental data to detect the possible anisotropic behaviour of the bedrock. The measured temperature that corresponds in the top $18 \mathrm{~m}$ and in depth greater than $85 \mathrm{~m}$ is not included in the following, since temperature is highly influenced by the air temperature and by bottom end effects.

Figs. 15 and 16 show the depth-average measured and numerical temperature evolution in B1 (heat parallel to the foliations) and in B3 and $\mathrm{B} 4$ (heat at $45^{\circ}$ to the foliations) respectively. The mean measured temperature is higher than the numerical one by $0.15^{\circ} \mathrm{C}, 0.13^{\circ} \mathrm{C}$ and $0.10^{\circ} \mathrm{C}$ for $\mathrm{B} 1, \mathrm{~B} 3$ and $\mathrm{B} 4$ respectively. This small difference can be attributed to the accuracy of the offset calibration procedure and/or to an underestimation of the mean thermal conductivity and of the heat input applied in the numerical analysis. However, the differences are in the same order along both directions (parallel and at an angle of $45^{\circ}$ to the bedding planes), indicating the absence of dominant anisotropic effects.

Fig. 17 shows the temperature evolution in the three boreholes
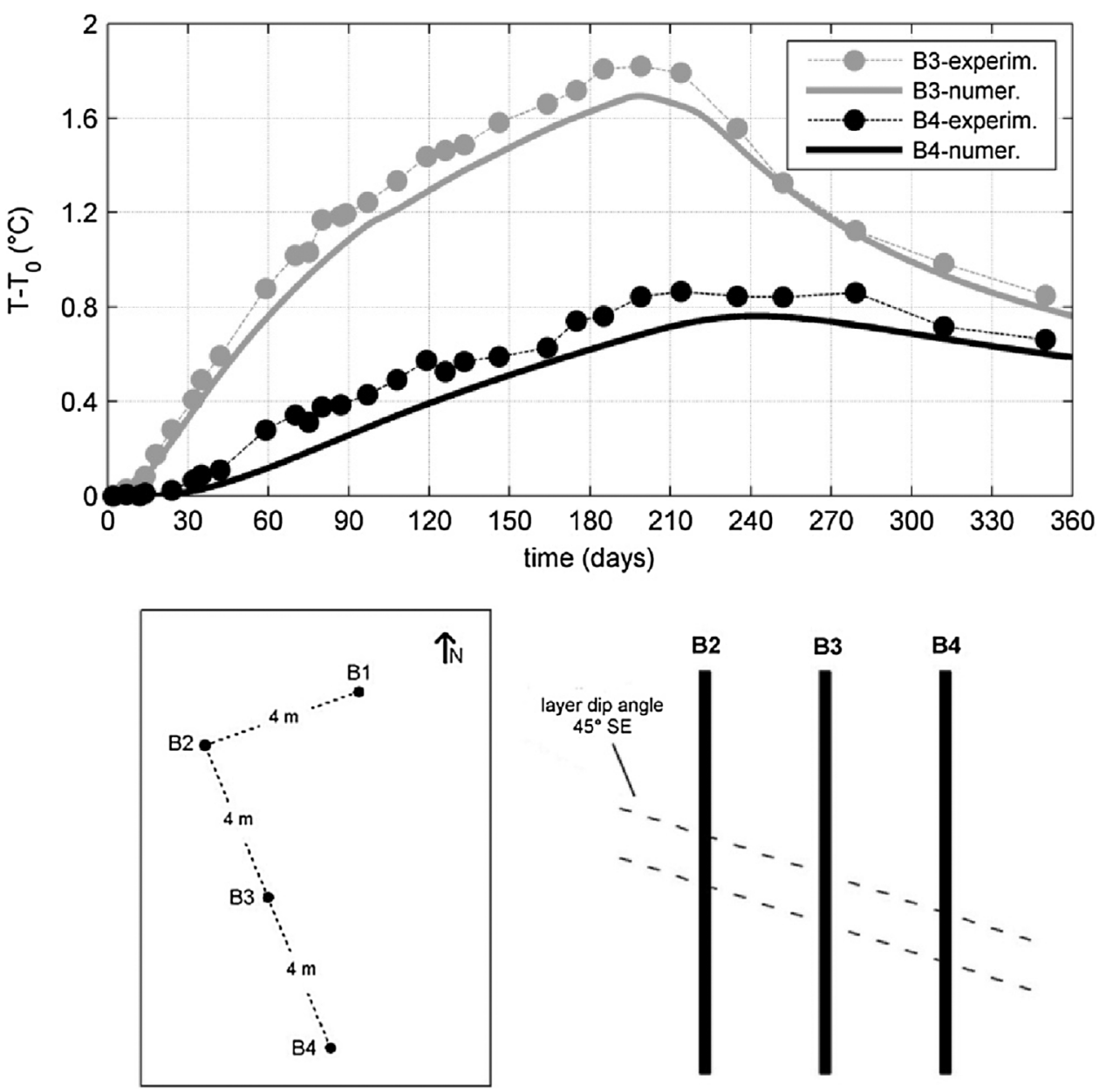

Fig. 16. Depth-average temperature increase evolution in B3 (top) and B4 (middle) during the TRT in B2. 

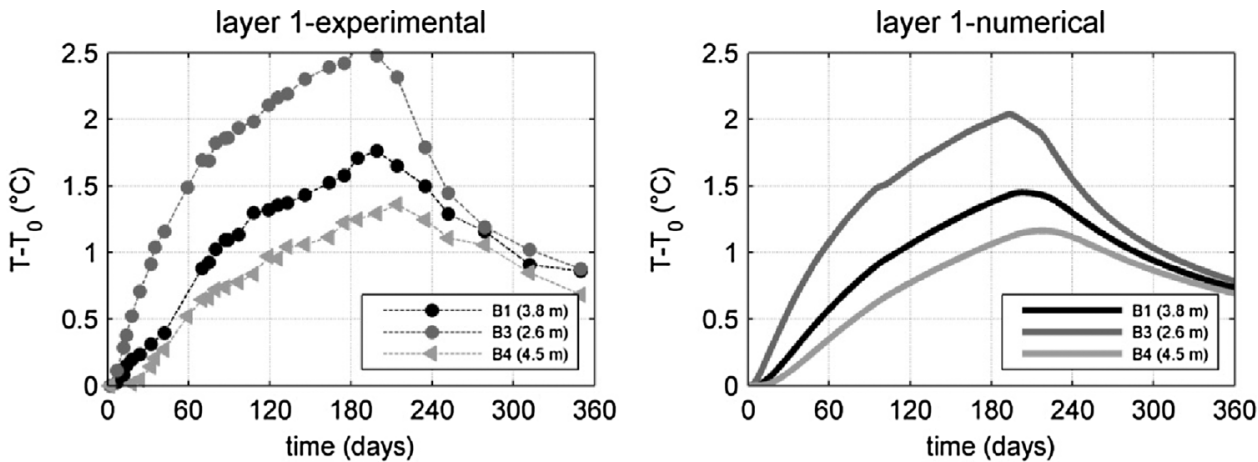

layer 2-experimental
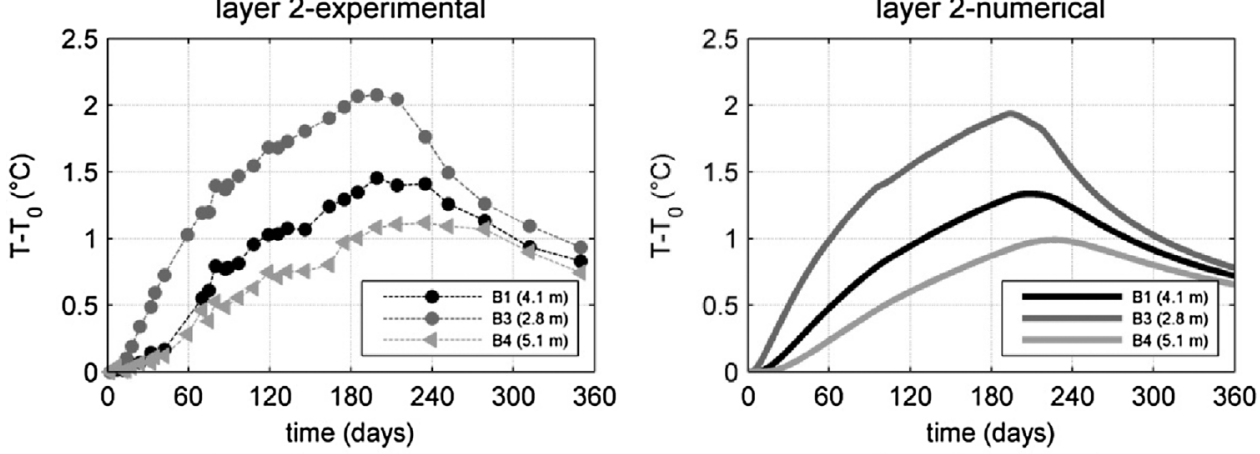

layer 3-experimental

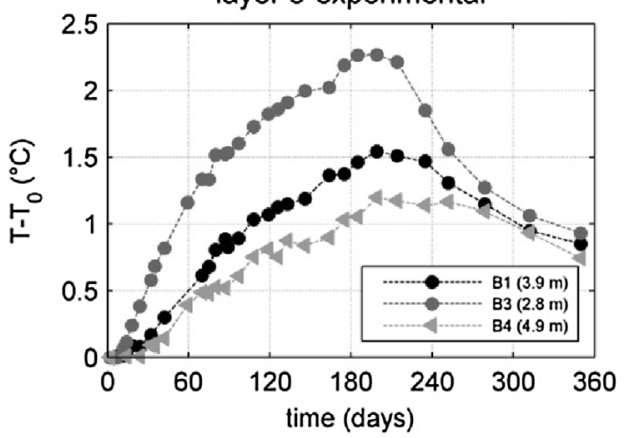

Fig. 17. Numerical and experimental temperature increase evolution along the same layers in B1, B3 and B4 during the TRT in B2 (layer 1: sandstone/ siltstone of $6.5 \mathrm{~m}$ thick at $\mathrm{z}=-77.4 \mathrm{~m}$ in $\mathrm{B} 1$, layer 2: shale/siltstone of $4.6 \mathrm{~m}$ thick at $\mathrm{z}=-60.8 \mathrm{~m}$ in B1, layer 3: shale/siltstone of $4.4 \mathrm{~m}$ thick at $\mathrm{z}=-68.4 \mathrm{~m}$ in $\mathrm{B} 1$ ). along the same layers. In all the layers, the highest temperature is observed in B3, which is closer to the heated BHE (B2), and the lowest temperature in $\mathrm{B} 4$, which has the greatest distance to the heated BHE. The temperature difference among the three numerical profiles at each layer is representative of the different distance to the heating source, since in the numerical model the bedrock is considered an homogenous and isotropic medium. The corresponding difference among the experimental profiles will include the distance effect as well as the potential anisotropy effect. The higher thermal diffusivity parallel to the foliations in the shale layers would be indicated by a greater difference in the experimental results between B1 and B3 (or B1 and B4) than in the numerical results. Table 3 summarizes the calculated experimental and numerical differences for thick layers. The differences between the experimental and the numerical profiles are the same along the sandstone/siltstone layer, where anisotropic effects are not expected to be dominant. Along the shale/siltstone layers, smaller differences are observed in the experimental data between B1 and the other two boreholes, which could indicate the lower effective shale thermal conductivity along the B2-B3-B4 plane. However, the difference between the numerical and experimental profiles at these layers is lower than $0.1{ }^{\circ} \mathrm{C}$, which can be attributed to the accuracy of the fiber optic measurements and the offset calibration procedure (section 2.2.1).

These results indicate that, in this case study, the shale anisotropic thermal behaviour does not have a significant effect on the thermal behaviour of the bedrock and that the measured temperature differences among the three boreholes are controlled by the varying distance to the heating source. The anisotropy effect would be more important in the case of greater difference between the effective shale thermal conductivity along two directions (e.g. parallel and perpendicular to the foliations) and of higher ratio of shale to sandstone layers.

\section{Conclusions}

In this case-study, the results of a typical-duration TRT $(60 \mathrm{~h})$ are representative of the BHE behaviour for longer heating periods and different modes (heating/recovery). The bedrock heterogeneity and the air temperature variations do not seem critical for the BHE modelling, as indicated by the good agreement between the numerical and the experimental results. However, the water temperature evolution is highly sensitive to the applied heating load, indicating the need for an accurate estimation of the energy needs of the building and the variable thermal loading during the operation of the system.

The temperature evolution in the surrounding bedrock is dominated by the distance to the heating source, the bedrock heterogeneity and the air temperature variations. Since layers of enhanced heat transfer are clearly detected in the recorder profiles, heterogeneity could be also critical in the case of thermal interaction between different operating BHEs. The heterogeneity effect could be further studied by developing a numerical model that considers the different layers. This would allow to quantify the in-situ, effective thermal diffusivity of different formations, study their thermal interaction at the in-situ scale and provide an indication of their potential of thermal energy storage. 
Table 3

Time-average temperature difference between the numerical and experimental profiles of the three boreholes (B1,B3,B4) along the same layers during the TRT in B2.

\begin{tabular}{lll}
\hline layer 1: sandstone/siltstone of $6.5 \mathrm{~m}$ thick $(-77.4 \mathrm{~m}$ depth in $\mathrm{B} 1)$ & experimental \\
\hline & numerical & 0.50 \\
\hline $\mathrm{DT}_{\mathrm{B} 3}-\mathrm{DT}_{\mathrm{B} 1}$ & 0.50 & 0.24 \\
$\mathrm{DT}_{\mathrm{B} 1}-\mathrm{DT}_{\mathrm{B} 4}$ & 0.24 & experimental \\
\hline layer $2:$ shale/siltstone of $4.6 \mathrm{~m}$ thick $(-60.8 \mathrm{~m}$ depth in B1) & 0.41 \\
\hline & numerical & 0.20 \\
\hline $\mathrm{DT}_{\mathrm{B} 3}-\mathrm{DT}_{\mathrm{B} 1}$ & 0.48 & \\
$\mathrm{DT}_{\mathrm{B} 1}-\mathrm{DT}_{\mathrm{B} 4}$ & 0.27 & experimental \\
\hline layer $3:$ shale/siltstone of $4.4 \mathrm{~m}$ thick $(-68.4 \mathrm{~m}$ depth in B1) & numerical & 0.46 \\
\hline
\end{tabular}

Moreover, bottom end effects are non-negligible at the rock mass temperature distribution, which indicates that the assumption of the BHE as an infinite heating source is not valid in the ground surrounding the bottom of the borehole. The influence of the end effects are observed not only close to the borehole (e.g. $\mathrm{r}=0.2 \mathrm{~m}$ ), but also at greater distance (e.g. $\mathrm{r}=5 \mathrm{~m}$ ) and becomes more important with increasing heating time. The shale anisotropic behaviour was not detected in the in-situ measurements, for a dip angle of $45^{\circ} \mathrm{SE}$. This effect might be important in the case of greater dip angles.

It should be noted that these conclusions correspond to a conduction dominated heat transfer case and are not be applicable in the case of dominant groundwater effects, where the TRT interpretation cannot provide a unique value for the effective thermal conductivity (Loveridge et al., 2013). The BHE behaviour could vary for the different applied modes (heat injection, heat extraction, recovery), depending on the characteristics of the aquifer, and TRT data of a long duration could be critical for verifying the modelling of the water flow characteristics.

\section{Acknowledgements}

The work undertaken in this paper is supported by the Walloon Region project Geotherwal no 1117492 and the F.R.S.-FNRS F.R.I.A. fellowship of Georgia Radioti. We also would like to thank the University service ARI for their support in the installation of the BHEs as well as our partners in the project, the ULB (Université Libre de Bruxelles) and the companies OREX and Geolys. We thank the company REHAU for providing the pipes and the commercial grouting materials.

\section{References}

Al-Khoury, R., Bonnier, P.G., 2006. Efficient finite element formulation for geothermal heating systems. Part II: transient. Int. J. Numer. Methods Eng. 67 (5), 725-745. http://dx.doi.org/10.1002/nme.1662.

Al-Khoury, R., Bonnier, P.G., Brinkgreve, B.J., 2005. Efficient finite element formulation for geothermal heating systems. Part I: steady-state. Int. J. Numer. Methods Eng. 63, 988-1013. http://dx.doi.org/10.1002/nme.1662.

Beier, R.A., Acuña, J., Mogensen, P., Palm, B., 2013. Borehole resistance and vertical temperature profiles in coaxial borehole heat exchangers. Appl. Energy 102 665-675. http://dx.doi.org/10.1016/j.apenergy.2012.08.007.
Blum, P., Campillo, G., Kölbel, T., 2011. Techno-economic and spatial analysis of vertical ground source heat pump systems in Germany. Energy 36 (5), 3002-3011. http://dx. doi.org/10.1016/j.energy.2011.02.044.

Cerfontaine, B., Radioti, G., Collin, F., Charlier, R., 2016. Formulation of a 1D finite element of heat exchanger for accurate modelling of the grouting behaviour: application to cyclic thermal loading. Renew. Energy 96, 65-79. http://dx.doi.org/10. 1016/j.renene.2016.04.034.

Charlier, R., Radu, J.-P., Collin, F., 2001. Numerical modelling of coupled transient phenomena. Revue Française de Génie Civil 5 (6), 719-741. http://dx.doi.org/10 1080/12795119.2001.9692324.

Choi, W., Ooka, R., 2016. Effect of disturbance on thermal response test, part 2: Numerical study of applicability and limitation of infinite line source model for interpretation under disturbance from outdoor environment. Renew. Energy 85, 1090-1105. http://dx.doi.org/10.1016/j.renene.2015.07.049.

Collin, F., Li, X.L., Radu, J.-P., Charlier, R., 2002. Thermo-hydro-mechanical coupling in clay barriers. Eng. Geol. 64, 179-193. http://dx.doi.org/10.1016/S0013-7952(01) 00124-7.

Delaleux, F., Py, X., Olives, R., Dominguez, A., 2012. Enhancement of geothermal borehole heat exchangers performances by improvement of bentonite grouts conductivity. Appl. Therm. Eng. 33-34 (1), 92-99.

Diao, N., Li, Q., Fang, Z., 2004. Heat transfer in ground heat exchangers with groundwater advection. Int. J. Therm. Sci. 43 (12), 1203-1211. http://dx.doi.org/10.1016/ j.ijthermalsci.2004.04.009.

Eppelbaum, L., Kutasov, I., Pilchin, A., 2014. Applied Geothermics, Lecture Notes in Earth System Sciences. Springer-Verlag, Berlin Heidelberg. http://dx.doi.org/10.1007/ 978-3-642-34023-9 1.

Erol, S., François, B., 2014. Efficiency of various grouting materials for borehole heat exchangers. Appl. Therm. Eng. 70, 788-799. http://dx.doi.org/10.1016/j. applthermaleng.2014.05.034.

Erol, S., Hashemi, M.A., François, B., 2015. Analytical solution of discontinuous heat extraction for sustainability and recovery aspects of borehole heat exchangers. Int. J. Therm. Sci. 88, 47-58. http://dx.doi.org/10.1016/j.ijthermalsci.2014.09.007.

Eskilson, P., 1987. Thermal Analysis of Heat Extraction Boreholes. Lund University, Sweden (Doctoral dissertation).

Gnielinski, V., 1976. New equations for heat and mass transer in turbulent pipe and channel flow. Int. J. Chem. Eng. 16 (2), 359-368.

Hellström, G., 1991. Ground Heat Storage: Thermal Analyses of Duct Storage Systems Lund University, Sweden (Doctoral dissertation).

Hermans, T., Nguyen, F., Robert, T., Revil, A., 2014. Geophysical methods for monitoring temperature changes in shallow low enthalpy geothermal systems. Energies 7, 5083-5118. http://dx.doi.org/10.3390/en7085083.

Li, M., Lai, A.C.K., 2015. Review of analytical models for heat transfer by vertical ground heat exchangers (GHEs): A perspective of time and space scales. Appl. Energy 151, 178-191. http://dx.doi.org/10.1016/j.apenergy.2015.04.070.

Loveridge, F., Holmes, G., Powrie, W., Roberts, T., 2013. Thermal response testing through the Chalk aquifer in London, UK. Proc. Inst. Civ. Eng. Geotech. Eng. 166 (2), 197-210. http://dx.doi.org/10.1680/geng.12.00037.

Luo, J., Rohn, J., Xiang, W., Bertermann, D., Blum, P., 2016. A review of ground investigations for ground source heat pump (GSHP) systems. Energy Build. 117, 
160-175. http://dx.doi.org/10.1016/j.enbuild.2016.02.038.

MIS 3005, 2008. Requirements for MCS Contractors Undertaking the Supply, Design, Installation, Set to Work, Commissioning and Handover of Microgeneration Heat Pump Systems. Department of Energy and Climate Change, London.

Marcotte, D., Pasquier, P., 2008. On the estimation of thermal resistance in borehole thermal conductivity test. Renew. Energy 33 (11), 2407-2415. http://dx.doi.org/10 1016/j.renene.2008.01.021.

Nguyen, D., Lanini, S., (2012). Projet Solargeotherm: modélisations numeériques de transferts thermiques dans le dispositif souterrain d'échange de chaleur. BRGM/RP-59697-FR, 91 p., 63 ill, 5 ann., don't ann. 5 sur DVD.

Ozudogru, T.Y., Ghasemi-Fare, O., Olgun, C.G., Basu, P., 2015. Numerical modeling of vertical geothermal heat exchangers using finite difference and finite element techniques. Geotech. Geol. Eng. 33, 291-306. http://dx.doi.org/10.1007/s10706-0149822-z.

Philippe, M., Bernier, M., Marchio, D., 2009. Validity ranges of three analytical solutions to heat transfer in the vicinity of single boreholes. Geothermics 38 (4), 407-413. http://dx.doi.org/10.1016/j.geothermics.2009.07.002.

Popov, Y.A., Pribnow, D.F.C., Sass, J.H., Williams, C.F., Burkhardt, H., 1999. Characterization of rock thermal conductivity by high-resolution optical scanning. Geothermics 28, 253-276. http://dx.doi.org/10.1016/S0375-6505(99)00007-3.

Radioti, G., Charlier, R., Nguyen, F., Radu, J.-P., 2013. Thermal response test in borehole heat exchangers equipped with fiber optics. In: Proceedings, International Workshop on Geomechanics and Energy: The Ground as Energy Source and Storage. EAGE, Lausanne, Switzerland. pp. 96-100.
Radioti, G., Delvoie, S., Sartor, K., Nguyen, F., Charlier, R., 2015. Fiber-optic temperature profiles analysis for closed-loop geothermal systems: a case study. In: Proceedings, Second EAGE Workshop on Geomechanics and Energy: The Ground as Energy Source and Storage. EAGE, Celle, Germany.

Radioti, G., Delvoie, S., Charlier, R., Dumont, G., Nguyen, F., 2016. Heterogeneous bedrock investigation for a closed-loop geothermal system: a case study. Geothermics 62, 79-92. http://dx.doi.org/10.1016/j.geothermics.2016.03.001.

Radioti, G., Sartor, K., Charlier, R., Dewallef, P., Nguyen, F., 2017. Effect of undisturbed ground temperature on the design of closed-loop geothermal systems: a case study in a semi-urban environment. Appl. Energy 200, 89-105. http://dx.doi.org/10.1016/j. apenergy.2017.05.070.

Self, S.J., Reddy, B.V., Rosen, M.A., 2013. Geothermal heat pump systems: status review and comparison with other heating options. Appl. Energy 101, 341-348. http://dx. doi.org/10.1016/j.apenergy.2012.01.048.

Singorelli, S., Bassetti, S., Pahud, D., Kohl, T., 2007. Numerical evaluation of thermal response tests. Geothermics 36, 141-166. http://dx.doi.org/10.1016/j.geothermics. 2006.10.006.

Smolarczyk, U., 2003. Geotechnical Engineering Handbook, vol. 2 Procedures, Berlin. Spitler, J.D., Gehlin, S., 2015. Thermal response testing for ground source heat pump systems-An historical review. Renew. Sustain. Energy Rev. 50, 1125-1137. http://dx. doi.org/10.1016/j.rser.2015.05.061.

Yavuzturk, C., Spitler, J.D., 1999. A short time step response factor model for vertical ground loop heat exchangers. ASHRAE Trans. 105 (2), 475-485. 